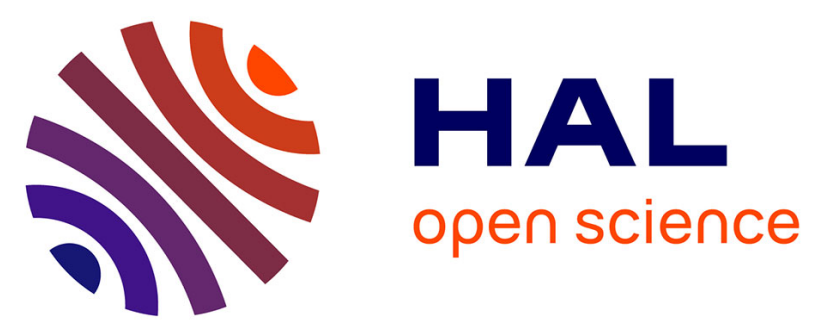

\title{
Comparing thermal tolerance across contrasting landscapes: first steps towards understanding how landscape management could modify ectotherm thermal tolerance
}

Kévin Tougeron, Joan van Baaren, Françoise Burel, Lucy Alford

\section{To cite this version:}

Kévin Tougeron, Joan van Baaren, Françoise Burel, Lucy Alford. Comparing thermal tolerance across contrasting landscapes: first steps towards understanding how landscape management could modify ectotherm thermal tolerance. Insect Conservation and Diversity, 2016, 9 (3), pp.171-180. 10.1111/icad.12153. hal-01290842

HAL Id: hal-01290842

https://hal-univ-rennes1.archives-ouvertes.fr/hal-01290842

Submitted on 18 Mar 2016

HAL is a multi-disciplinary open access archive for the deposit and dissemination of scientific research documents, whether they are published or not. The documents may come from teaching and research institutions in France or abroad, or from public or private research centers.
L'archive ouverte pluridisciplinaire HAL, est destinée au dépôt et à la diffusion de documents scientifiques de niveau recherche, publiés ou non, émanant des établissements d'enseignement et de recherche français ou étrangers, des laboratoires publics ou privés. 
1 This is a post-print version of the peer-reviewed paper originally published in Insect Conservation and Diversity 2 (2016) doi: 10.1111/icad.12153.

3

$4 \quad$ Title

5 Comparing thermal tolerance across contrasting landscapes: first steps towards understanding

6 how landscape management could modify ectotherm thermal tolerance.

7

\section{$8 \quad$ Running title}

$9 \quad$ Landscape influences insects' thermal tolerance

Authors

12 Kévin Tougeron ${ }^{1,2,3}$, Joan van Baaren ${ }^{1,2}$, Françoise Burel ${ }^{1,2}$ \& Lucy Alford $^{1,2}$

\section{Adresses}

${ }^{1}$ UMR 6553 Ecobio, Université de Rennes 1, 263 avenue du Général Leclerc, 35042 Rennes, France.

${ }^{2}$ Université Européenne de Bretagne (UEB), 5 boulevard Laënnec, 35000, Rennes, France.

${ }^{3}$ Institut de Recherche en Biologie Végétale, Département de sciences biologiques, Université de Montréal, 4101 Sherbrooke Est Montréal, Québec, Canada H1X 2B2.

\section{Corresponding author:}

Kévin Tougeron

E-mail: tougeron.kevin@gmail.com

Phone: (+33) 223234132 


\section{Abstract}

1. Insects are highly dependent on ambient temperatures to ensure their biological functions. Their persistence in the environment and their resistance to unfavorable temperatures are governed by their physiological thermal tolerance.

2. Global change extends beyond climatic conditions to encompass modifications to the landscape. However, studies of climate change and landscape composition effects on ecosystem services, such as biological control, are commonly performed independently. Moreover, coarse scales are not always relevant when assessing climate change's impacts on ectotherms. We aimed to better understand the ecological relationships that may exist between microclimatic variation and insect thermal tolerance across a landscape composition gradient.

3. To determine how landscape composition may impact insect thermal tolerance, parasitic wasps (Hymenoptera: Braconidae: Aphidiinae) of aphids were sampled along a landscape gradient from "closed" to "open" habitats. Sampling was performed during the winter 2013/14 and spring 2014 in cereal fields of Brittany, France. Meteorological data were recorded along this gradient.

4. First, our results show an influence of landscape composition on local microclimate. Additionally, parasitoids from open landscapes had a higher tolerance to low temperatures, leading to higher physiological costs, compared to parasitoids from closed landscapes. This trend was stronger in winter than in spring.

5. These results have numerous implications in the context of climate change, suggesting that targeted landscape management practices could create sheltered microclimatic areas that 
reduce the physiological costs of thermal tolerance, and promote the persistence of biological control agents.

Keywords: Climate change; Thermal biology; Critical temperatures; Insect ecophysiology; Landscape ecology; Conservation ecology; Biological pest control; Hymenoptera; Braconidae; Aphidiinae; Aphidius

\section{Introduction}

Climate models predict a global average temperature increase of between 1.7 and $6^{\circ} \mathrm{C}$ by the year 2100 (IPCC, 2013). In addition, an increase in the frequency of extreme events (heat or cold spells) is expected, especially in temperate regions (Hance et al., 2007). Meanwhile, European landscapes have undergone increasing homogenization since the 1950s due to agricultural intensification, leading to the removal of hedges, groves, woods, and natural grasslands (MEA, 2005). This homogenization has reduced the effectiveness of ecosystem services, such as pest control (Thies et al., 2011). Although the combined influences of landscape properties and climate change (warming winters, increased incidence of cold spells) on ecosystems are still poorly understood, there is increasing evidence that working on both of these aspects could yield more important insights than considering them separately.

Despite numerous reports of climate change impacts, the gap between the coarse scale at which climate data are collected and the climatic conditions the organisms actually experience at a finer scale is problematic (Bennie et al., 2008; Potter et al., 2013; Woods et al., 2015). Downscaling from global to microclimatic variations is needed to better investigate how ectotherms will respond to changes in their immediate environment. It is well known that 
local microclimate can be influenced by landscape properties (e.g. Chen et al., 1999). For instance, the windbreak and antifreeze role of hedges, especially those with an embankment, has been widely studied and confirmed in agricultural landscapes. Wooded and closed areas generally have lower temperature amplitudes than open areas over a daily scale (Argent, 1992; Suggitt et al., 2011), but are also colder, on average, than open areas due to the retention of cold air layers by hedges (Quénol \& Beltrando, 2006). The microclimatic variation that occurs between open and closed landscapes is a very complex phenomenon that depends on many elements such as slope, hedge density, topography, and solar radiation (Quénol \& Beltrando, 2006; Bennie et al., 2008; Suggitt et al., 2011).

In the context of conservation biology, and accepting the realities of climate change and landscape simplification, there is a need to understand whether microclimatic variation due to landscape composition affect ectotherm thermal tolerance. The existence of microclimates is widely confirmed, but the roles they play with regard to small organism ecology remains understudied (Potter et al., 2013; Sunday et al., 2014; Woods et al., 2015). Recent field studies (e.g. Suggitt et al., 2011; Pincebourde \& Woods, 2012; Lawson et al., 2014; Maclean et al., 2015) have demonstrated the importance of focusing on microclimatic variation when assessing organisms' susceptibility to climate change. These papers, along with the present study, represent the first steps towards understanding how insects will be affected by climate change at the scale of their local environment, and whether microclimatic variations due to landscape composition could allow them to exploit more favorable temperature conditions.

There is a particular need to identify the relative roles of evolution versus behavioral and physiological plasticity in moderating the impacts of global environmental changes (Deutsch et al., 2008; Sunday et al., 2014). Acclimatization (i.e., the capacity to better resist previously 
experienced temperatures) is an important physiological trait utilized by insects to cope with thermal stress. This is a well-known phenomenon that, along with behaviour, could be a plastic trait that commonly allows ectotherms to cope with climate change (Andrew \& Terblanche, 2013; Colinet et al., 2015). Body size, which is known to influence many life history traits in insects (Chown \& Gaston, 2010), could also influence their thermal tolerance. Indeed, the Absolute Energy Demand (AED) hypothesis predicts that larger individuals should be disadvantaged in the face of stressful temperature conditions, since they expend energy proportionally faster than smaller individuals (Reim et al., 2006).

This study examined the ecological relationships between the thermal tolerance of insects, microclimatic variation, and agricultural landscape composition (crop size, hedge length, type of soil cover). In particular, this work aimed to investigate how insects could adjust their phenotypic responses to temperature variation among landscapes. To address these issues, the cold tolerance and the size of aphid parasitoids, important biological control agents, were measured across a landscape composition gradient in Brittany, France. Many studies have been devoted to these species (e.g., Thies et al., 2005; Le Lann et al., 2008, 2014) including investigations of their thermal tolerance (Giri et al., 1982; Legrand et al., 2004; Le Lann et al., 2011a; b; Ismail et al., 2012). Aphid parasitoids are interesting biological models for landscape microclimate studies because they closely track the distribution of their hosts, especially during the larval stage when they are immobilized inside an aphid mummy and have to withstand the climatic conditions imposed upon them.

The following hypotheses were tested: (i) In the study area, microclimate varies along the landscape gradient, with temperatures in the closed landscape being on average colder but less variable than in the open landscape; (ii) If the first hypothesis is confirmed, the parasitoid 
thermal tolerance should be landscape-dependent, with parasitoids from open, more stressful areas being more cold tolerant; (iii) Due to their seasonal acclimatization capacities, and because exposure to unfavorable cold temperatures are less frequent in spring months, parasitoids should be more cold resistant in winter than in spring; (iv) Parasitoids are smaller in open areas than in closed areas; and (v) parasitoids are smaller in winter than in spring due to temperature differences between landscapes and seasons (following the AED hypothesis).

\section{Material and methods}

\section{Landscape gradient determination}

Parasitic wasps were monitored in winter wheat fields in northern Brittany (France). Sampling took place in the vicinity of the LTER 'Zone Atelier Armorique' (osur.univ-rennes1.fr/zaarmorique, $48^{\circ} 36^{\prime} \mathrm{N}, 1^{\circ} 32^{\prime} \mathrm{W}$ ) along a hedgerow network landscape gradient, ranging from closed landscapes to more open landscapes. To select the fields, 16 areas (300 meter radius) containing at least one wheat field were characterized with respect to the following three parameters: total hedge length (meters), average field size (hectares), and percentage grassland in the buffer zone. The land-cover over the past 5 years (2009-2013) was characterized, and only plots with annual cultures (maize or cereals) during the last 5 years were considered. This restriction was imposed in order to limit any potential effects of grasslands on arthropod communities. One wheat field was randomly selected from each area, and each area was then identified as belonging to one of three landscape units: (1) Closed landscape (five fields) - high grassland density (>45\%), many hedgerows (>3200m) and small field sizes (<0.93ha); (2) Intermediate landscape (six fields); (3) Open landscape (five fields) - low grassland density $(<20 \%)$, few hedgerows $(<550 \mathrm{~m})$ and larger fields $(>2.70 \mathrm{ha})$. 
See supplementary material for a map of the study area (Appendix S1), precise locations of the fields (Appendix S2), correlations between landscape variables (Appendix S3) and extreme values for the landscape gradient (Appendix S4). All of the selected fields were separated from one another by at least 600 meters. Although all fields were prospected, parasitoids were only found in 12 fields (4 per landscape type). All of the selected fields were managed with similar conventional agriculture practices. Preliminary results revealed no significant differences in insect thermal tolerance within landscape types. Accordingly, data from plots belonging to the same type of landscape were pooled in subsequent analyses.

\section{Sampling sessions and meteorological records}

To evaluate potential differences in insect thermal tolerance between seasons, two rounds of sampling were conducted: one in late winter (13 January to 7 March 2014) and one in early spring (24 March to 15 May 2014). Over the course of both sampling periods, local meteorological data were recorded using BWS200 weather stations (Campbell Scientific France) to characterize climate differences between seasons and among landscapes. One weather station per landscape type was used, with each recording air temperature, relative humidity (using CS215 probes accurate to $\pm 0.3^{\circ} \mathrm{C}$ and $\pm 2 \%$ respectively) and wind speed (using Wind Sentry anemometer accurate to $\pm 0.5 \mathrm{~m} \cdot \mathrm{s}^{-1}$ ) once an hour during the entire sampling period. Each station had a roof and was placed 1 meter above the ground. Each station was placed at least 15 meters from the hedge on flat ground. 


\section{Study species}

163 Aphidius parasitic wasps (Hymenoptera: Braconidae: Aphidiinae) are endoparasitoids of cereal aphids. These aphids (Sitobion avenae Fabricius, Rhopalosiphum padi L. and

165 Metopolophium dirhodum Walker) are present during the winter in Brittany, resulting in increased crop damage at the onset of spring (Le Ralec et al., 2010). Parasitoids are present throughout the year in Brittany with a succession of species between seasons (Krespi et al., 1994). In this study, Aphidius parasitoids were included in analyses, while secondary parasitoids were excluded due to their rarity in the fields early in the season. A total of 4 species were found during winter (Aphidius rhopalosiphi De Stefani-Perez, Aphidius matricariae Haliday, Aphidius avenae Haliday and Aphidius ervi Haliday) and 3 species in spring (A. rhopalosiphi, A. avenae and A. ervi).

\section{Sampling methods}

Parasitoids were sampled by collecting aphid mummies (i.e., parasitized aphids containing a parasitoid pupa). To assess the diversity and abundance of mummies, fields were visited twice a week during each sampling period. Sampling occurred during a 1 hour period over a surface of at least $1000 \mathrm{~m}^{2}$, with field borders excluded to avoid margin effects. Mummies of the three major species of cereal aphids described above were sampled (every mummy found was collected). The largest living aphids (larval stages L4 and above) were also sampled and kept in microcages to wait for possible mummification. Each microcage consisted of a plastic tube (5 $\mathrm{cm}$ diameter) in which wheat (Triticum aestivum L. v. Saturnus (Poaceae)) grew on a vermiculite substrate. The microcages were checked daily for 10 days and newly-formed mummies were conserved. Each mummy was placed individually in a gelatin capsule 
(Capsule T1 - Capsugel®) and subsequent parasitoid emergence was verified twice per day. Aphids, mummies and parasitoids were maintained in the laboratory after sampling at $20 \pm$ $1{ }^{\circ} \mathrm{C}, 70 \pm 10 \%$ relative humidity, and a photoperiod of L16:D8. The sex of parasitoids was determined, with individuals identified according to their collection site. Following thermal tolerance experiments (see below), parasitoids were freeze-killed at $-20^{\circ} \mathrm{C}$ and identified using an optical microscope and the identification key developed by Hullé et al. (2006). Host aphid species were also identified for each parasitoid using a binocular microscope. This enabled the determination of the composition of the parasitoid guild and the creation of quantitative food webs for both seasons. Comparisons of thermal tolerance and size between winter and spring-collected parasitoids were only made for A. rhopalosiphi, because it was the only species present in large numbers during both seasons.

\section{Cold tolerance measurement}

Non-lethal thermal thresholds are states of narcosis, offering a means of estimating the cold tolerance of individuals, which can have important effects on insect fitness (Le Lann et al., 2011a; Alford et al., 2012a). Insect physiological thermal tolerance is defined as the temperature range between the two thresholds of minimum critical temperature $\left(\mathrm{CT}_{\min }\right)$ and maximum temperature $\left(\mathrm{CT}_{\max }\right)$ beyond which survival is impossible (Bale, 1996). Indeed, survival is of little benefit if locomotion is compromised, leading to death through an inability to feed or to escape predators or parasites (Alford et al., 2012a; b). Here, we only focus on the $\mathrm{CT}_{\min }$ threshold. Indeed, in temperate climates insect fitness is expected to increase as temperature rises (Deutsch et al., 2008) while sudden cold spells in winter could have a major 
impact on parasitoid populations and could decrease the effectiveness of pest control in late winter and early spring.

To measure parasitoid cold tolerance $\left(\mathrm{CT}_{\min }\right)$, a double-walled glass column based on the model of Huey et al. (1992), and improved by Powell \& Bale (2006), was used. A cryostat (VWR-CryoBath®) was used to cool the tube. There was no temperature difference between the top and the bottom of the tube. Temperature was controlled using a thermocouple probe (accurate to $0.01^{\circ} \mathrm{C}$ ) connected to a digital display. A cooling rate of $0.75^{\circ} \mathrm{C} \cdot \mathrm{min}^{-1}$ was chosen to avoid inducing a rapid cold hardening response in the test insects (Powell \& Bale, 2006). Relative humidity in the tube, which could not be directly controlled, was $35 \pm 10 \%$. Each of the 272 parasitoids tested was individually placed in a tube. An individual's $\mathrm{CT}_{\min }$ was considered to have been reached when the parasitoid could no longer cling to the wall of the vertical column, and dropped from the tube wall (Le Lann et al., 2011a). After $\mathrm{CT}_{\text {min }}$ measurements, individuals were placed individually in Eppendorf ${ }^{\circledR}$ tubes and stored in the freezer. In order to avoid any confounding factors (temperature, atmospheric pressure, solar radiation in the laboratory), individuals originating from different field types were tested on each day of the experiments.

\section{Size measurements}

The size of parasitoids was measured after thermal tolerance experiments. The average length of each parasitoid's two hind tibia (a good proxy for parasitoid size) was measured and averaged. Images were captured with a Zeiss AxioCam ERc5s® HD camera mounted on a x9 binocular magnifier, and measurements (precise to $0.01 \mathrm{~mm}$ ) were performed with the Image ${ }^{\circledR}$ software (v. 1.48). 


\section{Statistical analyses}

Statistical analyses were performed using R software (R Development Core Team, 2013). Statistical analyses were carried out with a statistical error risk of 5\%. Statistical differences in meteorological data among landscape types were tested using a standard repeated measures ANOVA. The meteorological variable in question was considered as a fixed effect, and recording time included as a random effect. Tukey HSD post-hoc tests were used to detect pairwise differences among landscape types for each season. Homogeneity of species distributions among landscapes was tested using a Chi-square test of homogeneity for each season. A generalized linear model (GLM) was fitted to parasitoid $\mathrm{CT}_{\min }$ data in both seasons, with landscape type, parasitoid species, sex, size, aphid host, parasitoid species x landscape interaction, and parasitoid species $\mathrm{x}$ aphid host species interaction as explanatory variables. The effect of these explanatory variables was tested with the "Anova" function from the "car" package, which performs an analysis of variance (Type II) with likelihood ratio tests, using a chi-square statistic (Fox \& Weisberg, 2011). Tukey HSD post-hoc tests for linear models were then performed to test for differences within categories. $\mathrm{CT}_{\min }$ differences between seasons were tested using a Mann-Whitney test. Kruskal-Wallis tests were used to test if the landscape had an effect on the size of parasitoid individuals in each season. For $A$. rhopalosiphi, two GLMs were fitted and tested as described above. The $\mathrm{CT}_{\min }$ response of parasitoids to season $\mathrm{x}$ sex and season $\mathrm{x}$ size interactions, and of their size to a season $\mathrm{x}$ sex interaction were tested. Differences within seasons where then evaluated with Mann-Whitney tests. 


\section{Results}

254

255

256

257

\section{Meteorological records}

For both seasons, closed landscapes were on average significantly colder than open landscapes (Table 1). With respect to its amplitude and standard deviation, temperature varied less in closed landscapes than in intermediate and open landscapes. In winter, closed and intermediate landscapes had a higher relative humidity than open landscapes. Closed landscapes had a lower wind speed than intermediate and open landscapes. The weather in winter was on average colder, with greater wind exposure and humidity than in spring for all landscape types. There was more variation among landscapes in winter than in spring for all of the meteorological variables measured. The occurrence of days which contained at least one temperature event under zero were for closed, intermediate and open landscapes respectively, 1, 2, and 4 in winter and 0,0 , and 4 in spring.

Please insert Table 1 here

\section{Parasitoid communities}

The parasitoid community (Fig. 1) was dominated by A. rhopalosiphi in winter and spring. The second most abundant species was A. matricariae in winter, although this species was completely absent in spring. A. avenae was the second most abundant species in spring. The aphid community was dominated by $R$. padi in winter and $M$. dirhodum in spring. In winter, A. matricariae and A. ervi were never reared from $M$. dirhodum. In spring, parasitoids were reared from different host species in accordance with the hosts' relative abundance. The species were homogeneously distributed across all landscape types in both winter (Chisquared test, $\left.\chi^{2}=7.88, \mathrm{df}=6, \mathrm{p}=0.25\right)$ and spring $\left(\chi^{2}=1.32, \mathrm{df}=4, \mathrm{p}=0.86\right)$. 
Please insert Figure 1 here.

Thermal tolerance

279

\section{All parasitoid species}

Figure 2 shows the data for all species (pooled) for both seasons. Statistical information is provided in Table 2. For all species and across all landscapes, the winter parasitoid community was significantly more cold resistant than the spring community $\left(-0.64 \pm 0.07^{\circ} \mathrm{C}\right.$ in winter and $-0.44 \pm 0.05^{\circ} \mathrm{C}$ in spring, Mann-Whitney test, $\mathrm{W}=10273, \mathrm{p}<0.05$ ).

In winter, there was a significant effect of landscape type on $\mathrm{CT}_{\min }$. Individuals from open environments were significantly more cold resistant than those from intermediate (Tukey HSD, $\mathrm{z}=-2.48, \mathrm{p}<0.05)$ and closed $(\mathrm{z}=-3.53, \mathrm{p}<0.01)$ environments. There was a marginally non-significant difference between individuals from intermediate and closed environments $(\mathrm{z}=-2.22, \mathrm{p}=0.06)$. A similar but non-significant trend was observed for spring populations. In spring, a significant effect of host species was found; parasitoids reared from M. dirhodum had significantly lower $\mathrm{CT}_{\min }$ than those reared from $S$. avenae $\left(-0.51 \pm 0.06^{\circ} \mathrm{C} \mathrm{n}=98\right.$ and -0.20 $\pm 0.09^{\circ} \mathrm{C} \mathrm{n}=39$ respectively, Tukey HSD, $\left.\mathrm{z}=2.76, \mathrm{p}<0.05\right)$. There were no differences between the $\mathrm{CT}_{\min }$ of parasitoids reared from $R$. padi compared to those reared from other species. There were no significant differences in $\mathrm{CT}_{\min }$ among species or between sexes, neither in winter or spring. There was no effect of body size on $\mathrm{CT}_{\min }$ for either winter or springcollected parasitoids, and parasitoid size was not influenced by the landscape gradient in winter (Kruskal-Wallis test, $\chi^{2}=3.03, \mathrm{df}=2, \mathrm{p}=0.22$ ) or spring $\left(\chi^{2}=0.13, \mathrm{df}=2, \mathrm{p}=0.94\right)$. There were no interaction effects among landscape gradient, parasitoid species, or aphid host species affecting the $\mathrm{CT}_{\min }$ of parasitoids in winter or spring. 


\section{For A. rhopalosiphi only}

303

Winter sampled individuals from all types of landscape were more resistant to cold than those sampled in the spring (respectively $-0.66 \pm 0.08^{\circ} \mathrm{C}$ and $-0.45 \pm 0.04^{\circ} \mathrm{C}$, Anova, $\mathrm{LR}=3.32, \mathrm{df}=1$, $\mathrm{p}=0.05)$. There was no difference in $\mathrm{CT}_{\min }$ between sexes in either season $(\mathrm{LR}=0.001, \mathrm{df}=1$, $\mathrm{p}=0.93$ ). There was no influence of parasitoids' body size on their thermal tolerance for either sex $(\mathrm{LR}=0.63, \mathrm{p}=0.42)$. Furthermore, there was no effect of the interaction between season and $\operatorname{sex}(\mathrm{LR}=0.56, \mathrm{df}=1, \mathrm{p}=0.46)$ or between season and size $(\mathrm{LR}=0.75, \mathrm{df}=1, \mathrm{p}=0.39)$ on parasitoids' $\mathrm{CT}_{\min }$ (Fig. 3a). Winter-collected A. rhopalosiphi individuals were smaller than spring individuals (respectively and for both sexes, $0.50 \pm 0.01 \mathrm{~mm}$ and $0.58 \pm 0.01 \mathrm{~mm}$, $\mathrm{LR}=57.84, \mathrm{df}=1, \mathrm{p}<0.001)$. There was no effect of the interaction between season and sex on parasitoid body size $(\mathrm{LR}=0.65, \mathrm{df}=1, \mathrm{p}=0.42)$. In both seasons, size differed significantly between sexes $(\mathrm{LR}=13.03, \mathrm{df}=1, \mathrm{p}<0.001)$. Females were significantly larger than males in winter $(0.52 \pm 0.01 \mathrm{~mm}$ and $0.47 \pm 0.01 \mathrm{~mm}$ respectively, Mann-Whitney test, $\mathrm{W}=1067, \mathrm{p}<0.01)$ and spring (respectively $0.58 \pm 0.01 \mathrm{~mm}$ and $0.55 \pm 0.01 \mathrm{~mm}, \mathrm{~W}=1098, \mathrm{p}<0.01$ ) (Fig. 3b).

Please insert Figure $3 a$ and $3 b$ here

\section{Discussion}

The results confirmed our first and second hypotheses, highlighting a landscape composition effect on different climatic factors and on the cold tolerance of parasitoids. This effect was more pronounced in winter. This study also revealed that parasitoids were smaller and more 
cold resistant in the winter than in spring, in accordance with our third and fifth hypotheses. Parasitoid size was not affected by the landscape gradient, which refutes our fourth hypothesis.

\section{Landscape effects on microclimate}

Between an open area and a hedged zone or forest remnant, there is generally a decrease in daytime temperatures but an increase in humidity (Argent, 1992; Quénol \& Beltrando, 2006). These tendencies were confirmed by our measurements in winter and, to a lesser extent, in spring. Indeed, hedgerows usually limit wind speed, which acts to increase relative humidity. Additionally, cooling typically occurs along the borders of hedges and in the fields behind them. These important shelter effects limit the mixing of air layers and thus accentuate the cooling of fields surrounded by hedgerows (Quénol \& Beltrando, 2006). Another consequence of sheltered environments is that temporal variations in temperature and humidity are less pronounced than in open landscapes (Suggitt et al., 2011; also confirmed by our results). In spring, temperature is less variable among landscapes than in winter, since vegetation begins to grow in the fields, and hedgerow foliage increases in density. The present study showed that open landscapes, especially in winter, present more stressful climatic conditions for ectotherms such as wind exposure, frost, more extreme temperatures, and greater temperature variation.

\section{Landscape effects on the cold tolerance}

We demonstrated the importance of considering microhabitat variation when assessing organisms' susceptibility to climate change. Winter sampled parasitoids from open landscapes 
were approximately $1{ }^{\circ} \mathrm{C}$ more resistant to cold than those from closed landscapes, and $0.6^{\circ} \mathrm{C}$ more resistant than individuals from intermediate landscape. The magnitude of these effects greatly decreased in spring, although a similar trend was observed. Differences in parasitoid $\mathrm{CT}_{\min }$ along the landscape gradient may have resulted from phenotypic plasticity (acclimatization), which is a particularly effective way for insects to cope with temperature stresses at different temporal scales (Lee \& Denlinger, 2010; Colinet et al., 2015). The thermal conditions encountered during the larval stage greatly influences the thermal tolerance of adults in most insects (Hoffmann et al., 2013), and in open landscapes, parasitoids are less protected against cold spells. Thus, parasitoids from open landscapes could have acclimatized to sudden colder temperatures during their development, resulting in greater adulthood cold resistance. The results of Bahrndorff et al. (2006) on springtails and Bauerfeind \& Fischer (2014) on butterflies also support the contention that thermal extremes explain variation in thermal resistance traits better than average temperatures. Separating the effects of mean and extreme temperatures on ectotherms - a recently developing field of research in thermal biology (Easterling et al., 2000; Thompson et al., 2013; Colinet et al., 2015) - is one of the novelties of this study. In sheltered environments, parasitoids might be better able to resist cold due to higher relative humidity, and therefore might have no need to develop the strong physiological resistance required of open landscape parasitoids. Indeed, as suggested by De Bach (1943), desiccation is one of the main reasons for death under cold stress conditions in Aphidiinae. Higher humidity facilitates cold resistance by diminishing the risks of desiccation (Bahrndorff et al., 2006; Hoffmann et al., 2013).

Winter temperatures are stressful for parasitoids, since they are often below the insects' developmental thresholds. The thermal threshold for mummy-to-adult development has been 
estimated at $7.2^{\circ} \mathrm{C}$ for A. rhopalosiphi, $7.9^{\circ} \mathrm{C}$ for $A$. matricariae, and $6.6^{\circ} \mathrm{C}$ for $A$. ervi (Sigsgaard, 2000; Colinet \& Hance, 2010). In spring, however, temperatures become warmer on average and less extreme. Thus, even if microclimatic differences along the landscape gradient persist (as it has been shown in this study), the temperatures reached are rarely or never stressful enough to make parasitoid acclimatization necessary. For this reason, it may not be possible to reveal differences between landscapes with respect to the cold tolerance of spring-collected parasitoids. In spring, the microclimatic gradient effect could also be compensated by a smaller scale impact of vegetation within the plots. For example, it has previously been shown that vegetation cover in crops provides a stable and beneficial microhabitat for insects both in terms of temperature and wind exposure (Waterhouse, 1955). Nevertheless, as shown in this study for A. rhopalosiphi, parasitoid cold tolerance differs between seasons. Winter-collected individuals acclimatized to cold temperatures are therefore more resistant to cold and vice versa in spring, supporting our third hypothesis.

There were no effects of sex or parasitoid species on cold tolerance in winter or spring. Parasitoids of all species emerging from S. avenae in spring were less cold tolerant than those emerging from $M$. dirhodum. We can thus infer bottom-up effects of host quality on parasitoid thermal tolerance. It is already known that parasitoids emerging from $S$. avenae are larger than parasitoids emerging from other aphid species (which increases their fecundity), and that parasitoids emerging from $R$. padi have a higher emergence rate (Andrade et al., 2013). A trade-off may then exist between cold resistance and other life history traits that determine host choice and availability. 


\section{Size effects}

392 In our analysis of $A$. rhopalosiphi, female parasitoids were larger than males. This trend is 393 almost ubiquitous among parasitoid wasps (Hurlbutt, 1987) and insects in general (Chown \& 394 Gaston, 2010). There was no direct effect of size on the individuals' thermal tolerance 395 between landscapes, although A. rhopalosiphi individuals were smaller in winter than in 396 spring. If we consider that mean winter temperatures recorded are really those experienced by 397 the parasitoids in the fields (i.e., there may have been specific locations with higher temperatures), this result does not follow the predictions of the temperature-size rule (TSR). The TSR states that insects developing at higher temperatures are generally smaller upon

400

401 emergence as a result of shorter development time (Van der Have \& De Jong, 1996). Our results are, however, consistent with the AED hypothesis which states that a winter should impose a selective pressure that favors smaller parasitoids. For instance, Ismail et al. (2012) showed that smaller individuals of the parasitoid A. ervi that smaller individuals had have better resistance to cold stress than larger wasps. Since parasitoid size is intimately linked to fitness-related traits (e.g. fecundity, longevity; Harvey et al., 1994), there could be a size induced trade-off between female fertility (large individuals) and survival (reduced size) under stressful temperature conditions. These results showing an effect of temperature variations at the seasonal scale (but not at the landscape scale) confirm our fifth hypothesis but refutes our fourth hypothesis concerning parasitoid size.

\section{Conclusion}

A clear impact of the landscape on the thermal tolerance of parasitoids in winter, and to a lesser extent in spring, was observed in this study. The physiological thermal tolerance of 
parasitoids seemed to respond to the varying weather conditions (especially extreme temperatures and relative humidity) encountered among landscapes and also among seasons. As stated in the introduction, broad scale temperature variations and predictions can be very different from those directly experienced by insects. These data highlight the need to better understand the relationship between insect physiology and landscape structure, especially under stressful conditions. We must use fine scale studies combined with information on the microhabitat if we are to understand climate change effects on insect populations and individual physiology. Climate change effects could be exacerbated by agricultural intensification leading to more open landscapes, subjecting insects to increasing physiological stress in the future. From a biological control perspective, our results imply that it may be possible to manipulate parasitoid cold resistance using protective elements in the landscape that reduce microclimatic variations.

\section{Acknowledgments}

The authors gratefully acknowledge Paul Abram for improving the use of English in the manuscript, Hervé Quénol for his help with analysis and interpretation of the meteorological data, Colette Bertrand and Romain Georges for their help in characterizing the landscape gradient, Alban Thomas and Valérie Bonnardot for their help in getting temperature data from the field, Stéphanie Llopis, Hervé Amat, Emeline Bouchet and Mathilde Méheut for technical support in the field and in the lab, Valérie Briand for bibliographic support, Jean-Sébastien Pierre for help with statistical analysis, and two anonymous referees for very helpful comments. KT was granted by the French Région Bretagne and the Marie Curie IEF CLIMLAND (FP7-PEOPLE-2012-IEF-326943) awarded to LA, FB and JVB. The 
experiments comply with the current laws of the country in which the experiments were performed.

\section{References}

Alford, L., Blackburn, T.M. \& Bale, J.S. (2012a) Effects of acclimation and latitude on the activity thresholds of the aphid Myzus persicae in Europe: Variation in aphid activity thresholds. Journal of Applied Entomology, 136, 332-346.

Alford, L., Hughes, G.E., Blackburn, T.M. \& Bale, J.S. (2012b) Walking speed adaptation ability of Myzus persicae to different temperature conditions. Bulletin of Entomological Research, 102, 303-313.

Andrade, T.O., Hervé, M., Outreman, Y., Krespi, L. \& van Baaren, J. (2013) Winter host exploitation influences fitness traits in a parasitoid. Entomologia Experimentalis et Applicata, 147, 167-174.

Andrew, N.R. \& Terblanche, J.S. (2013) The response of insects to climate change. (Salinger, J. ed.). Climate of Change: Living in a Warmer World, pp. 38-50, CSIRO Publishing, Auckland, New-Zealand.

Argent, R.M. (1992) The influence of a plant canopy on shelter effect. Journal of Wind Engineering \& Industrial Aerodynamics, 41, 2643-2653.

Bahrndorff, S., Holmstrup, M., Petersen, H. \& Loeschcke, V. (2006) Geographic variation for climatic stress resistance traits in the springtail Orchesella cincta. Journal of Insect Physiology, 52, 951-959.

Bale, J.S. (1996) Insect cold hardiness: A matter of life and death. European Journal of Entomology, 93, 369-382.

Bauerfeind, S.S. \& Fischer, K. (2014) Simulating climate change: temperature extremes but not means diminish performance in a widespread butterfly. Population Ecology, 56, $239-250$.

Bennie, J., Huntley, B., Wiltshire, A., Hill, M.O. \& Baxter, R. (2008) Slope, aspect and climate: Spatially explicit and implicit models of topographic microclimate in chalk grassland. Ecological Modelling, 216, 47-59.

Chen, J., Saunders, S.C., Crow, T.R., Naiman, R.J., Brosofske, K.D., Mroz, G.D., Brookshire, B.L. \& Franklin, J.F. (1999) Microclimate in Forest Ecosystem and Landscape 
Ecology: Variations in local climate can be used to monitor and compare the effects of different management regimes. BioScience, 49, 288-297.

Chown, S.L. \& Gaston, K.J. (2010) Body size variation in insects: a macroecological perspective. Biological Reviews, 85, 139-169.

Colinet, H., Sinclair, B.J., Vernon, P. \& Renault, D. (2015) Insects in Fluctuating Thermal Environments. Annual Review of Entomology, 60, 123-140.

Colinet, H. \& Hance, T. (2010) Interspecific variation in the response to low temperature storage in different aphid parasitoids. Annals of Applied Biology, 156, 147-156.

De Bach, P. (1943) The effect of low storage temperature on reproduction in certain parasitic Hymenoptera. Pan-Pacific Entomologist, 19, 112-119.

Deutsch, C.A., Tewksbury, J.J., Huey, R.B., Sheldon, K.S., Ghalambor, C.K., Haak, D.C. \& Martin, P.R. (2008) Impacts of climate warming on terrestrial ectotherms across latitude. Proceedings of the National Academy of Sciences, 105, 6668-6672.

Easterling, D.R., Meehl, G.A., Parmesan, C., Changnon, S.A., Karl, T.R. \& Mearns, L.O. (2000) Climate Extremes: Observations, Modeling, and Impacts. Science, 289, 20682074.

Fox, J. \& Weisberg, H.S. (2011) An R Companion to Applied Regression, 2nd ed. Sage.

Giri, M.K., Pass, B.C., Yeargan, K.V. \& Parr, J.C. (1982) Behavior, net reproduction, longevity, and mummy-stage survival of Aphidius matricariae [Hym. Aphidiidae]. Entomophaga, 27, 147-153.

Hance, T., van Baaren, J., Vernon, P. \& Boivin, G. (2007) Impact of Extreme Temperatures on Parasitoids in a Climate Change Perspective. Annual Review of Entomology, 52, 107-126.

Harvey, J.A., Harvey, I.F. \& Thompson, D.J. (1994) Flexible Larval Growth Allows Use of a Range of Host Sizes by a Parasitoid Wasp. Ecology, 75, 1420-1428.

Hoffmann, A.A., Chown, S.L. \& Clusella-Trullas, S. (2013) Upper thermal limits in terrestrial ectotherms: how constrained are they? Functional Ecology, 27, 934-949.

Huey, R.B., Crill, W.D., Kingsolver, J.G. \& Weber, K.E. (1992) A method for rapid measurement of heat or cold resistance of small insects. Functional Ecology, 6, 489494.

Hullé, M., Turpeau, E. \& Chaubet, B. (2006) Encyclop'aphid, a key for aphids and their parasitoids 
Hurlbutt, B. (1987) Sexual size dimorphism in parasitoid wasps. Biological Journal of the Linnean Society, 30, 63-89.

IPCC. (2013) Climate Change 2013 the Physical Science Basis: Final Draft Underlying Scientific-Technical Assessment: Working Group I Contribution to the IPCC Fifth Assessment Report. (Stocker, T.F., D. Qin, G.-K. Plattner, M. Tignor, S.K. Allen, J. Boschung, A. Nauels, Y. Xia, V. Bex and P.M. Midgley eds.). 1535p., Cambridge University Press, Cambridge, United Kingdom and New York, NY, USA.

Ismail, M., Vernon, P., Hance, T., Pierre, J.-S. \& van Baaren, J. (2012) What are the possible benefits of small size for energy-constrained ectotherms in cold stress conditions? Oikos, 121, 2072-2080.

Krespi, L., Dedryver, C.A., Rabasse, J.-M. \& Nénon, J.P. (1994) A morphometric comparison of aphid mummies containing diapausing vs. non-diapausing larvae of Aphidius rhopalosiphi (Hymenoptera: Braconidae). Bulletin of Entomological Research, 84, 45-50.

Lawson, C.R., Bennie, J., Hodgson, J.A., Thomas, C.D. \& Wilson, R.J. (2014) Topographic microclimates drive microhabitat associations at the range margin of a butterfly. Ecography, 37, 732-740.

Lee, R.E.J. \& Denlinger, D.L. (2010) Rapid cold-hardening: Ecological significance and underpinning mechanisms. (Lee, R.E.J. \& Denlinger, D.L. eds.). Low Temperature Biology of Insect, pp. 35-58, Cambridge University Press, NY, USA.

Legrand, M.A., Salin, C., Langer, A. \& Hance, T. (2004) Are mummy characteristics reliable indicators of diapause and cold tolerance in the parasitoid wasp Aphidius rhopalosiphi (Braconidae, Aphidiinae)? CryoLetters, 25, 161-166.

Le Lann, C., Outreman, Y., Van Alphen, J.J.M., Krespi, L., Pierre, J.-S. \& Van Baaren, J. (2008) Do past experience and competitive ability influence foraging strategies of parasitoids under interspecific competition? Ecological Entomology, 33, 691-700.

Le Lann, C., Roux, O., Serain, N., Van Alphen, J.J.M., Vernon, P. \& Van Baaren, J. (2011a) Thermal tolerance of sympatric hymenopteran parasitoid species: does it match seasonal activity? Physiological Entomology, 36, 21-28.

Le Lann, C., Wardziak, T., van Baaren, J. \& van Alphen, J.J.M. (2011b) Thermal plasticity of metabolic rates linked to life-history traits and foraging behaviour in a parasitic wasp: Temperature affects physiology and behaviour of a parasitoid. Functional Ecology, 25, 641-651.

Le Lann, C., Visser, B., Mériaux, M., Moiroux, J., van Baaren, J., van Alphen, J.J.M. \& Ellers, J. (2014) Rising temperature reduces divergence in resource use strategies in coexisting parasitoid species. Oecologia, 174, 967-977. 
Le Ralec, A., Anselme, C., Outreman, Y., Poirié, M., Van Baaren, J., Le Lann, C. \& Van Alphen, J.J.-M. (2010) Evolutionary ecology of the interactions between aphids and their parasitoids. Comptes rendus biologies, 333, 554-565.

Maclean, I.M.D., Hopkins, J.J., Bennie, J., Lawson, C.R. \& Wilson, R.J. (2015) Microclimates buffer the responses of plant communities to climate change. Global Ecology and Biogeography, 24, 1203-1362.

Millennium Ecosystem Assessment. (2005) Ecosystems and Human Well-Being: Biodiversity Synthesis, World Resources Institute. Washington, DC.

Pincebourde, S. \& Woods, H.A. (2012) Climate uncertainty on leaf surfaces: the biophysics of leaf microclimates and their consequences for leaf-dwelling organisms. Functional Ecology, 26, 844-853.

Potter, K.A., Arthur Woods, H. \& Pincebourde, S. (2013) Microclimatic challenges in global change biology. Global Change Biology, 19, 2932-2939.

Powell, S.J. \& Bale, J.S. (2006) Effect of long-term and rapid cold hardening on the cold torpor temperature of an aphid. Physiological Entomology, 31, 348-352.

Quénol, H. \& Beltrando, G. (2006) Microclimate in forest ecosystem and landscape ecology. Climatologie, 3, 9-23.

R Development Core Team. (2013) R: A Language and Environment for Statistical Computing. R Foundation for Statistical Computing, Vienna, Austria.

Reim, C., Teuschl, Y. \& Blanckenhorn, W.U. (2006) Size-dependent effects of larval and adult food availability on reproductive energy allocation in the Yellow Dung Fly. Functional Ecology, 20, 1012-1021.

Sigsgaard, L. (2000) The temperature-dependent duration of development and parasitism of three cereal aphid parasitoids, Aphidius ervi, A. rhopalosiphi, and Praon volucre. Entomologia Experimentalis et Applicata, 95, 173-184.

Suggitt, A.J., Gillingham, P.K., Hill, J.K., Huntley, B., Kunin, W.E., Roy, D.B. \& Thomas, C.D. (2011) Habitat microclimates drive fine-scale variation in extreme temperatures. Oikos, 120, 1-8.

Sunday, J.M., Bates, A.E., Kearney, M.R., Colwell, R.K., Dulvy, N.K., Longino, J.T. \& Huey, R.B. (2014) Thermal-safety margins and the necessity of thermoregulatory behavior across latitude and elevation. Proceedings of the National Academy of Sciences, 111, 5610-5615.

Thies, C., Roschewitz, I. \& Tscharntke, T. (2005) The landscape context of cereal aphidparasitoid interactions. Proceedings of the Royal Society B: Biological Sciences, 272, 203-210. 
Thies, C., Haenke, S., Scherber, C., Bengtsson, J., Bommarco, R., Clement, L.W., Ceryngier, P., Dennis, C., Emmerson, M., Gagic, V. \& others. (2011) The relationship between agricultural intensification and biological control: experimental tests across Europe. Ecological Applications, 21, 2187-2196.

Thompson, R.M., Beardall, J., Beringer, J., Grace, M. \& Sardina, P. (2013) Means and extremes: building variability into community-level climate change experiments. Ecology Letters, 16, 799-806.

Van der Have, T.M. \& De Jong, G. (1996) Adult size in ectotherms: temperature effects on growth and differentiation. Journal of Theoretical Biology, 183, 329-340.

Waterhouse, F.L. (1955) Microclimatological profiles in grass cover in relation to biological problems. Quarterly Journal of the Royal Meteorological Society, 81, 63-71.

Woods, H.A., Dillon, M.E. \& Pincebourde, S. (2015) The roles of microclimatic diversity and of behavior in mediating the responses of ectotherms to climate change. Journal of Thermal Biology, 218, 1956-1967.

\section{Figures}

Winter 2014

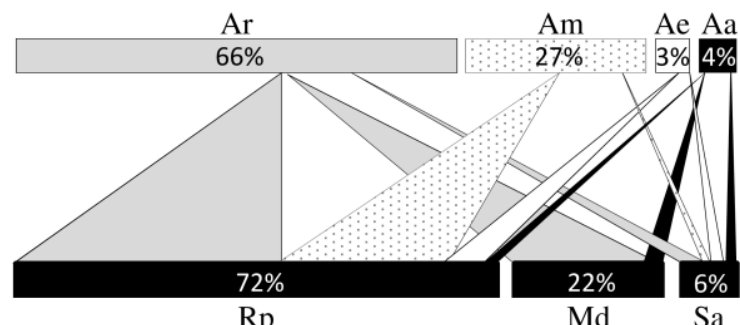

Spring 2014

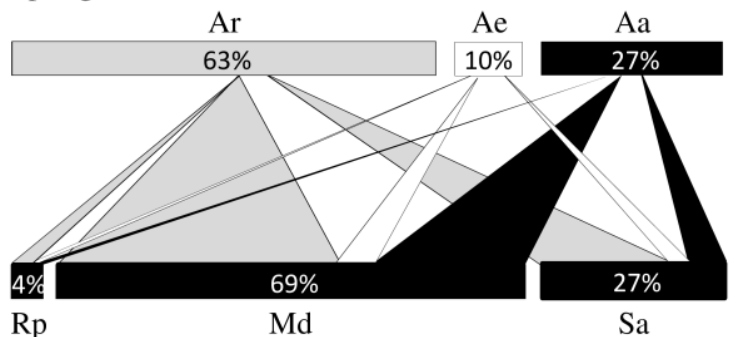

Figure 1: Quantitative food webs of the parasitoid and aphid community composition in winter and spring 2014.

Ar (Aphidius rhopalosiphi), Am (Aphidius matricariae), Ae (Aphidius ervi), Aa (Aphidius avenae), Rp (Rhopalosiphum padi), Md (Metopolophium dirhodum), Sa (Sitobion avenae). Upper bars represent parasitoid relative abundance and lower bars represent aphid relative abundance for each species. The thickness of the arrows between two bars is proportional to the relative number of trophic interactions between species (e.g. in winter $56 \%$ of the parasitoids emerged from $R$. padi mummies were $A$. rhopalosiphi). The figures do not include individuals that could not be identified. The total number of individuals are $n=127$ and $n=141$ for parasitoids and $n=141$ and $n=142$ for aphids in winter and spring, respectively. 
Figure 2: Average critical thermal minimum of parasitoids (all species) in winter and spring depending on the type 599 of landscape. $\mathrm{N}=127$ and 145 in winter and spring, respectively. Lower-case letters show significant differences 600 between landscapes for each season. For inter-seasonal comparisons refer to the text.

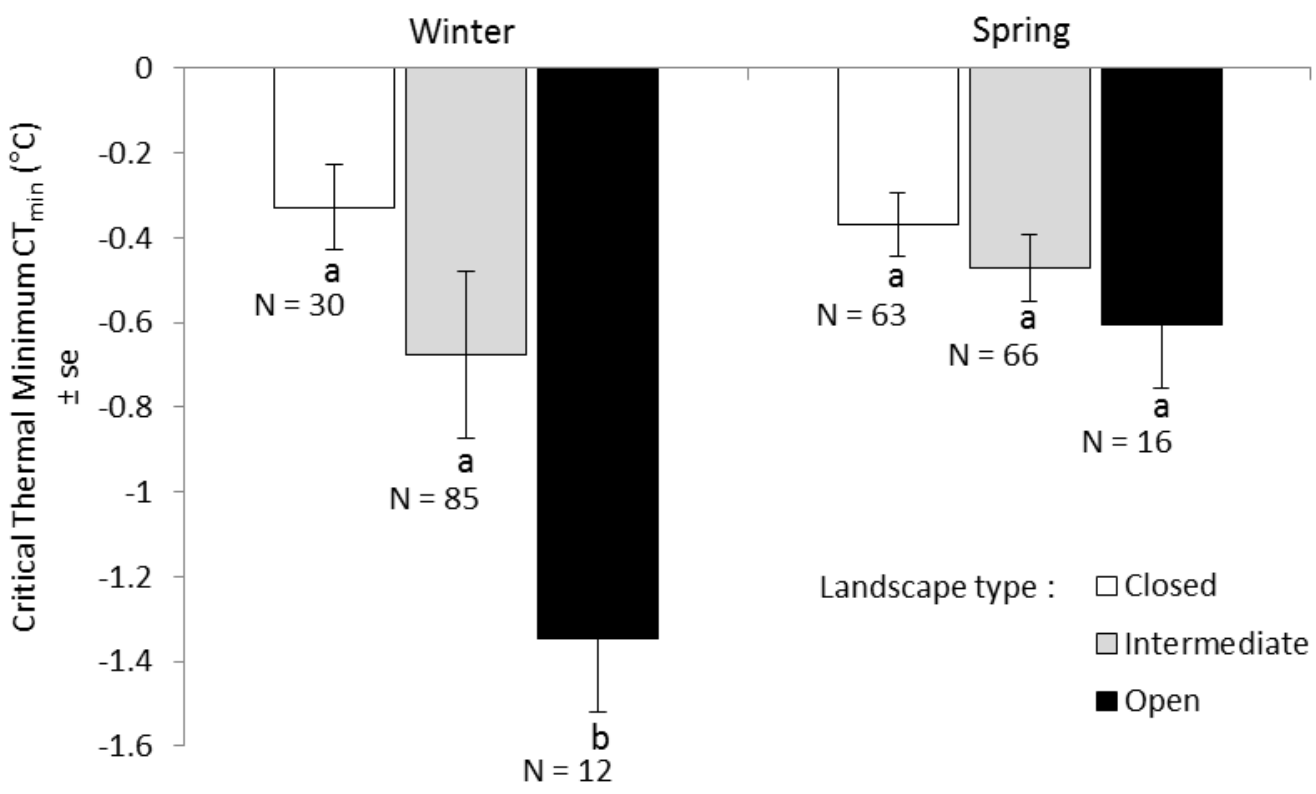

601

602

603 Figure 3: Average critical minimal temperature (a) and average tibia length (b) for A. rhopalosiphi in winter and 604 spring. $\mathrm{N}=172$ for $\mathrm{CT}_{\min }$ measurements and 163 for size measurements. Symbols indicate parasitoids sexes 605 males $(\precsim)$ and females $(+)){ }^{* \star *} p<0.001{ }^{* *} p<0.01{ }^{*} p<0.05$ n.s. $=$ not significant.
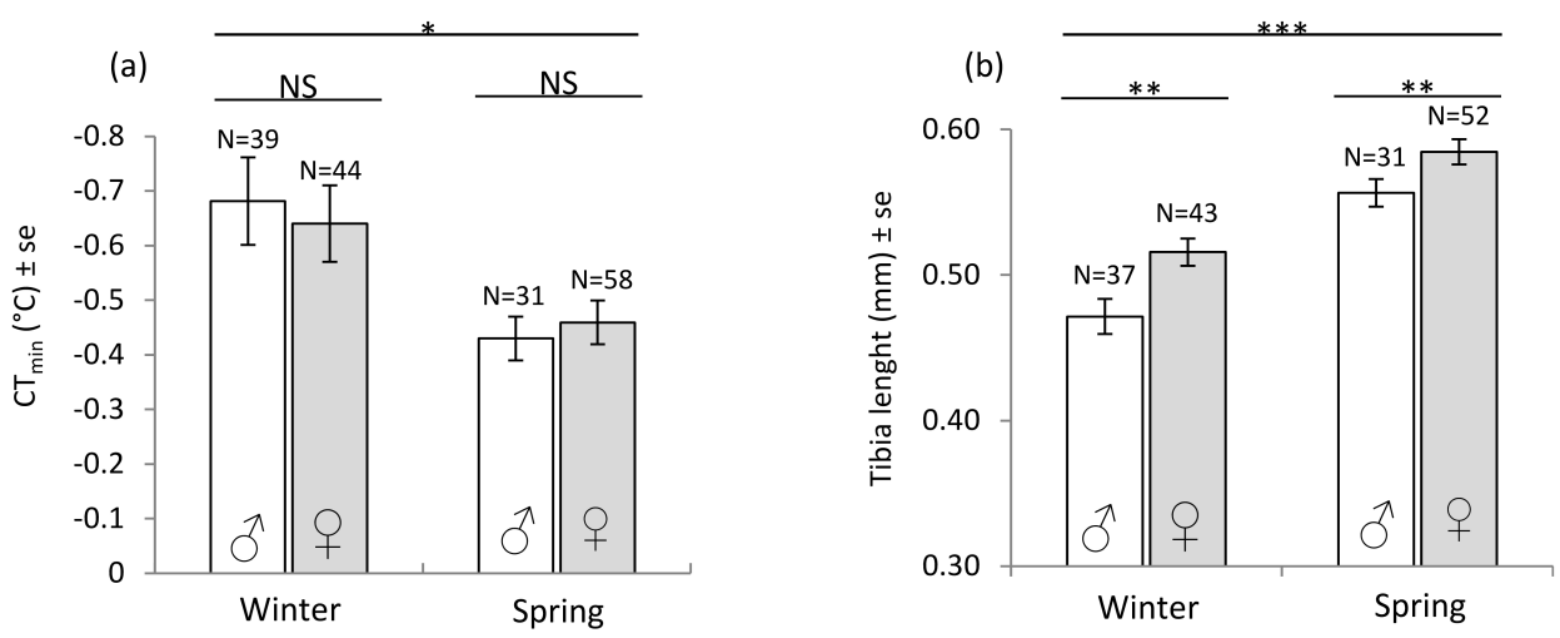


\begin{tabular}{|c|c|c|c|c|c|}
\hline Season & $\begin{array}{l}\text { Landscape } \\
\text { type }\end{array}$ & $\begin{array}{l}\text { Air temperature } \\
\left({ }^{\circ} \mathrm{C}\right)\end{array}$ & $\begin{array}{l}\text { Min | Max } \\
\text { temperature } \\
\left({ }^{\circ} \mathrm{C}\right)\end{array}$ & $\begin{array}{l}\text { Relative } \\
\text { humidity (\%) }\end{array}$ & $\begin{array}{l}\text { Wind speed } \\
\left(\mathrm{m} . \mathrm{s}^{-1}\right)\end{array}$ \\
\hline \multicolumn{6}{|c|}{ Landscape comparison } \\
\hline \multirow[t]{4}{*}{ Winter } & Closed & $6.58 \pm 0.07^{(a)}$ & $-0.32 \mid 14.61$ & $90.82 \pm 0.25^{(\mathbf{a})}$ & $2.18 \pm 0.04^{\text {(a) }}$ \\
\hline & Intermediate & $7.23 \pm 0.08^{(\mathbf{b})}$ & $-0.53 \mid 23.37$ & $90.18 \pm 0.25^{(a)}$ & $3.39 \pm 0.06^{(b)}$ \\
\hline & Open & $8.39 \pm 0.16^{(\mathrm{c})}$ & $-2.07 \mid 24.91$ & $85.82 \pm 0.54^{(\mathbf{b})}$ & $2.67 \pm 0.07^{(\mathrm{c})}$ \\
\hline & ANOVA (df=2) & $\begin{array}{l}F=67.01 \\
p<0.001\end{array}$ & & $\begin{array}{l}F=67.8 \\
p<0.001\end{array}$ & $\begin{array}{l}F=148.2 \\
p<0.001\end{array}$ \\
\hline \multirow[t]{4}{*}{ Spring } & Closed & $10.78 \pm 0.10^{(\mathrm{a})}$ & $0.51 \mid 20.10$ & $83.63 \pm 0.40$ & $1.84 \pm 0.03^{(a)}$ \\
\hline & Intermediate & $11.12 \pm 0.11^{(\mathbf{a}, \mathbf{b})}$ & $0.08 \mid 20.89$ & $84.46 \pm 0.38$ & $1.91 \pm 0.04^{(\mathrm{a})}$ \\
\hline & Open & $11.49 \pm 0.12^{(\mathbf{b})}$ & $-1.02 \mid 21.78$ & $83.66 \pm 0.43$ & $2.71 \pm 0.05^{(b)}$ \\
\hline & ANOVA $(\mathrm{df}=2)$ & $F=10.1, p<0.001$ & & n.s. & $\begin{array}{l}F=130.4 \\
p<0.001\end{array}$ \\
\hline \multicolumn{6}{|c|}{ Seasonal comparison } \\
\hline Winter & All & $7.12 \pm 0.05$ & $-2.07 \mid 24.91$ & $89.70 \pm 0.18$ & $2.77 \pm 0.03$ \\
\hline Spring & All & $11.13 \pm 0.06$ & $-1.02 \mid 21.78$ & $83.91 \pm 0.23$ & $2.16 \pm 0.03$ \\
\hline
\end{tabular}

Table 1: Daily average meteorological data ( \pm standard error) in the study area (Brittany, France) in winter $\left(13^{\text {th }}\right.$ January to $7^{\text {th }}$ March) and spring ( $24^{\text {th }}$ March to $15^{\text {th }}$ May) for different types of landscape. Results of repeated measures ANOVA comparing meteorological factors among landscapes are shown. n.s.=not significant. Superscript letters $(a, b, c)$ denote significant differences among landscapes for each meteorological factor within each season.

614

615

616 
Table 2: Factors influencing parasitoid $\mathrm{CT}_{\min }$. Test statistics from Generalized Linear Models (GLMs) are shown

622 for winter ( $N=127$ individuals, 72 females and 45 males) and spring ( $N=142$ individuals, 80 females and 62

623 males). There were large differences in community assembly between seasons so they had to be tested

624 separately; see text of Results. The Likelihood-Ratio chi-square is calculated for each model using the "car"

625 package. ${ }^{* * *} p<0.001 .{ }^{* *} p<0.01 .{ }^{*} p<0.05$.

\begin{tabular}{|c|c|c|c|c|c|c|c|}
\hline Factor/Season & & & Winter & & & & Spring \\
\hline & $\operatorname{LR}\left(\chi^{2}\right)$ & $\mathrm{df}$ & $p>\chi^{2}$ & & $\operatorname{LR}\left(\chi^{2}\right)$ & $\mathrm{df}$ & $p>\chi^{2}$ \\
\hline Landscape & 10.16 & 2 & $<0.01$ & ** & 3.43 & 2 & 0.18 \\
\hline Parasitoid species & 0.99 & 3 & 0.80 & & 0.62 & 2 & 0.73 \\
\hline Landscape : Parasitoid species & 0.56 & 2 & 0.76 & & 1.69 & 3 & 0.64 \\
\hline Sex & 0.53 & 1 & 0.47 & & 0.39 & 1 & 0.53 \\
\hline Host species & 1.17 & 2 & 0.42 & & 7.26 & 2 & $<0.05$ \\
\hline Parasitoid species : Host species & 2.16 & 4 & 0.71 & & 0.31 & 4 & 0.98 \\
\hline Parasitoid size & 1.96 & 1 & 0.16 & & 0.48 & 1 & 0.49 \\
\hline
\end{tabular}

626

627

628

629

630

631

632

633

634

635

636

637

638

639

640 


\section{Supplementary material:}

642 Appendix S1: Map of the sampling zone in northern Brittany (France) with the approximate location of the 16 643 fields sampled. The map includes a zoom on the specific area of the "ZA Armorique" where land cover is fully 644 described, in order to give the reader an idea of the landscape composition gradient. Numbers in the cursors refer 645 to corresponding numbers in Table 3 that give precise geographic locations.

646

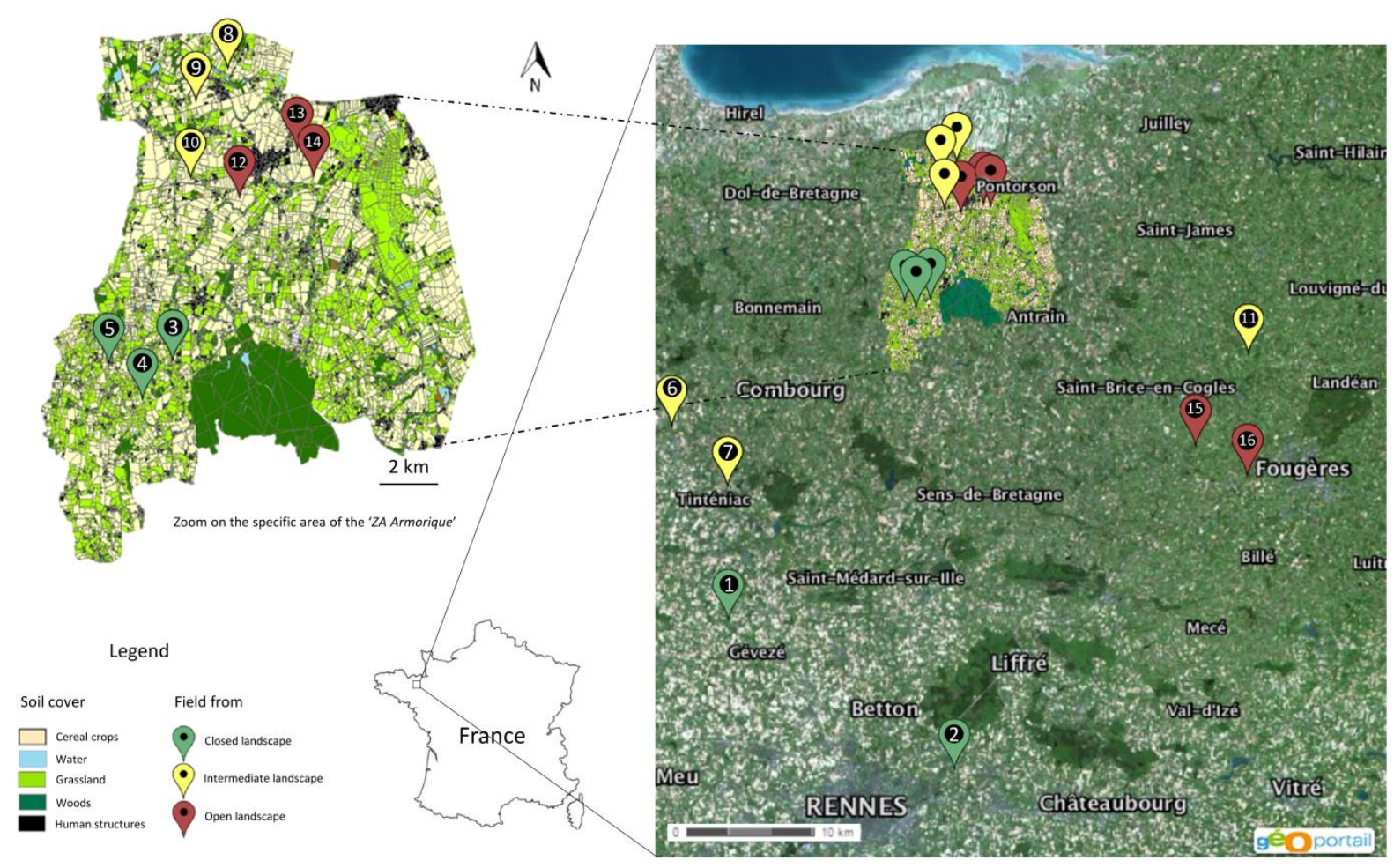

648

649

650

651

652

653

654

655

656 
658 on the map (Appendix S1).

\begin{tabular}{llll}
\hline Landscape type & Field number & Latitude $\left({ }^{\circ} \mathrm{N}\right)$ & Longitude $\left({ }^{\circ} \mathrm{W}\right)$ \\
\hline Closed & 1 & 48.230 & 1.832 \\
& 2 & 48.123 & 1.539 \\
& 3 & 48.482 & 1.603 \\
& 4 & 48.479 & 1.612 \\
\hline Intermediate & 5 & 48.482 & 1.625 \\
& 6 & 48.304 & 1.862 \\
& 7 & 48.301 & 1.828 \\
& 8 & 48.546 & 1.599 \\
& 9 & 48.557 & 1.575 \\
Open & 10 & 48.527 & 1.600 \\
& 11 & 48.469 & 1.274 \\
& 12 & 48.513 & 1.610 \\
& 13 & 48.534 & 1.548 \\
& 14 & 48.529 & 1.541 \\
& 15 & 48.383 & 1.349 \\
& 16 & 48.366 & 1.307 \\
\hline
\end{tabular}

660 Appendix S3: Correlations between the three variables used for landscape gradient determination. The variables 661 were highly correlated and it was impossible to avoid this correlation for landscapes in northern Brittany. We did 662 not consider the separate effect of each variable as it is commonly done in landscape ecology studies, but we did 663 test the effect of the combination of the three variables on microclimatic conditions. Thus, this study deals with a 664 "complexity gradient" or "closed to open gradient".

\begin{tabular}{llll}
\hline Correlation between variables $\left(\mathrm{R}^{2}\right)$ & Hedge length $(\mathrm{m})$ & Crop size $(\mathrm{ha})$ & Proportion of grasslands $(\%)$ \\
\hline Hedge length $(\mathrm{m})$ & 1 & & \\
Crop size $(\mathrm{ha})$ & -0.81 & 1 & \\
Proportion of grasslands $(\%)$ & 0.45 & -0.55 & 1 \\
\hline
\end{tabular}

665

666

667 Appendix S4: Variable values for the two $300 \mathrm{~m}$ radius buffers (on 16 areas described) situated at the minimum 668 and maximum extremes of the landscape gradient. High hedge length, small crop size and high proportion 669 grassland are characteristic of the more "closed" buffer, while short hedge length, large crop size, and high 670 proportion grassland characterize the more "open" buffer.

\begin{tabular}{lll}
\hline Extreme values & Minimum & Maximum \\
\hline Hedge length $(\mathrm{m})$ & 200 & 4653 \\
Crop size (ha) & 0.93 & 3.36 \\
Proportion grassland (\%) & 0.01 & 87 \\
\hline
\end{tabular}

671 